\title{
Aplikasi Visualisasi 3D Pada Struktur Sistem Rangka Manusia Berbasis Android
}

\author{
Satya Arisena Hendrawan ${ }^{1)}$, Rizal Isnanto ${ }^{2)}$, Ike Pertiwi Windasari ${ }^{2)}$ \\ Program Studi Sistem Komputer Fakultas Teknik Universitas Diponegoro \\ Jalan Prof. Sudharto, Tembalang, Semarang, Indonesia \\ satya.arisena9@gmail.com
}

\begin{abstract}
The development of information technology has penetrated into various aspects of human life that it can perform an active role on information technology. In learning, for instance in the world of education, there are many simply interactive applications run on Android operating system. This application employs Unity 3D software as an editor. The initial step of making this final project is creating a design of user interface application. Waterfall Development used as methodology for developing this application. Stages of research method, requirements, design, implementation, testing, and maintenance. User application is capable to run all menus contained on the application of "3D Visualization of Human Skeleton Structure System". With this application android-based user can exercise anytime and anywhere, and this application can run well when tested using black-box and got positive results when tested to application user.
\end{abstract}

Keywords: applications, technological development, education, android

\section{PENDAhuluan}

$\mathrm{D}$ ALAM era globalisasi saat ini, perkembangan teknologi semakin berkembang demikian pesatnya. Dalam kehidupan sehari-hari, teknologi informasi dan komunikasi merupakan sektor yang paling dominan. Peran teknologi tidak lagi sebagai elemen pendukung, melainkan elemen penting setelah sandang, pangan, dan papan. Adanya teknologi memudahkan siapa pun untuk belajar dan mendapatkan informasi yang dibutuhkan dari mana saja, kapan saja dan dari siapa saja.

Perkembangan dunia teknologi informasi merambah ke berbagai sisi kehidupan manusia untuk dapat berperan aktif dalam penggunaan perangkat lunak multimedia dalam proses belajar mengajar akan lebih meningkatkan efisien, meningkatkan motivasi, memfasilitasi belajar eksperimental, konsisten dengan belajar yang berpusat pada siswa atau mahasiswa dan mampu belajar lebih ${ }^{[1]}$.

Dalam bidang pendidikan kurikulum, sekolah menengah atas (SMA) ada silabus mata pelajar di bidang IPA (Ilmu Pengetahuan Alam) lebih spesfifiknya adalah adanya mata pelajaran mengenai struktur rangka tubuh manusia. Pihak sekolah pun harus mengadakan dan menggunakan alat peraga rangka tubuh manusia agar terciptanya visual atau gambaran bagi pelajar dan guru mudah membantu proses pengajaran dengan baik.

Pesatnya perkembangan teknologi khususnya dalam hal bidang teknologi informasi yang menggunakan perangkat lunak
Untuk memanfaatkan dari perkembangan teknologi tersebut, dilakukannya penelitian yang diharapkan dapat menjadi salah satu aplikasi media pembelajaran mengenai dan mengenal bagian-bagian dari kerangka tulang manusia secara visualisasi 3D pada smartphone Android.

\section{LANDASAN TEORI}

\section{A. Visualisasi}

Visualisasi adalah rekayasa dalam pembuatan gambar, diagram atau animasi untuk penampilan suatu informasi. Secara umu, visualisasi dalam bentuk gambar baik yang bersifat abstrak maupun nyata telah dikenal sejak awal dari peradaban manusia. Contoh dari hal itu meliputi lukisan di dinding-dinding gua dari manusia purba, bentuk huruf hiroglip Mesir, sistem geometri Yunani, dan teknik pelukisan dari Leonardo da Vinci untuk tujuan rekayasa dan ilmiah. ${ }^{[4]}$.

\section{B. Grafika Komputer}

Grafika komputer pada dasarnya adalah suatu bidang komputer yang mempelajari cara-cara untuk meningkatkan dan memudahkan komunikasi antara manusi dan mesin (komputer) dengan jalan membangkitkan, menyimpan, dan memanipulasi gambar model suatu objek menggunakan komputer ${ }^{[5]}$.

\section{Gambar Dua Dimensi}

Gambar dua dimensi (2D) memiliki karakteristik hanya memperlihatkan sumbu $x$ dan sumbu $y$ atau sumbu koordinat kartesius dua dimensi (2D). Transformasi dua dimensi dibagi sebagai berikut ${ }^{[6]}$.

1. Translasi adalah perpindahan objek dari titik P ke titik P' secara linier.

2. Penyekalaan (scaling) adalah perpindahan objek dari titik $\mathrm{P}$ ke titik P', dimana jarak titik P' adalah $m$ kali titik P.

3. Rotasi adalah perpindahan objek dari titik P ke titik P' yang pemindahan berputar sebesar sudut $\alpha$. Pada

\section{Gambar Tiga Dimensi}

Gambar tiga dimensi (3D) berbeda dengan dua dimensi 2D yang memperlihatkan sumbu $x$ dan sumbu $y$. Objek tiga dimensi (3D) merupakan sekumpulan titik-titik 3-D $(x, y, z)$ yang membentuk luasan-luasan yang digabungkan menjadi satu kesatuan ${ }^{[6]}$. Transformasi tiga dimensi dibagi sebagai berikut.

1. Translasi

Translasi adalah proses untuk memindahkan objek ke arah sumbu $x$, sumbu $y$ dan sumbu $z$ sebesarnya $(d x, d y, d z)$.

\section{Rotasi}

Pemutaran atau rotasi tiga dimesi (3D) lebih rumit 
dibandingkan pemutaran dua dimensi (2D), tetapi dasarnya sama yaitu bahwa pemutaran bisa dilaksanakan dengan memilih satu sumbu ${ }^{[5]}$.

\section{E. Struktur Rangka Manusia}

Struktur rangka manusia dapat dikelompokkan menjadi dua bagian poros tubuh dan bagian alat gerak. Fungsi dari rangka manusia salah satunya yaitu sebagai alat melekatnya otot-otot tubuh, melindungi organ penting manusia seperti otak, paruparu dan lain-lain.

\section{F. Android}

Android adalah sebuah sistem operasi untuk perangkat lunak mobile berbasis linux yang mencakup sistem operasi, middleware dan aplikasi. Android menyediakan platform terbuka bagi para pengembang untuk menciptakan aplikasi. Android di ambil alih oleh Google pada tahun 2005 dari Android, Inc sebagai bagian dari strategi untuk mengisi pasar sistem operasi bergerak. Google mengambil alih seluruh hasil kerja android termasuk tim yang mengembangkan Android.

Google menginginkan agar android bersifat terbuka dan gratis, oleh karena itu hampir setiap kode program Android diluncurkan berdasarkan lisensi open source Apache yang berarti bahwa setiap orang yang ingin menggunakan Android dapat men-download penuh source code nya ${ }^{[11]}$.

\section{G. Unity $3 D$}

Unity 3D adalah sebuah tool yang terintegrasi untuk membuat game, arsitektur bangunan dan simulasi. Unity tidak dirancang untuk proses atau modelling, dikarenakan Unity bukan tool untuk mendesain. Jika ingin mendesain 3D menggunakan editor lainnya seperti 3DsMax, Blender atau editor lainnya.Fitur scripting yang disediakan, mendukung 3 bahasa pemrograman yaitu diantaranya : JavaScript, C\#, dan Boo.

\section{H. Google SketchUp 8}

Google SketchUp yaitu perangkat lunak desain grafis yang dikembangkan oleh Google, dikembangkan pada tahun 1999 sebagai tujuan umum alat pembuatan konten 3D. SketchUp yang dirancang untuk arsitek, insinyur sipil, pembuat film, game developer, dan profesi terkait.

\section{Metodologi Pengembangan Waterfall}

Metode waterfall merupakan pendekatan yang sistematis dan beruurtan pada pengembangan perangkat lunak [14] . Pengembangan dimulai dengan menentukan spesifikasi kebutuhan dan berlanjut melalui tahapan berikutnya. Tahapan yang secara umum dilalui adalah analisis kebutuhan, perancangan, implementasi pengujian dan pemeliharaan [13] Pada Gambar 1 menunjukkan metode pengembangan Waterfall.

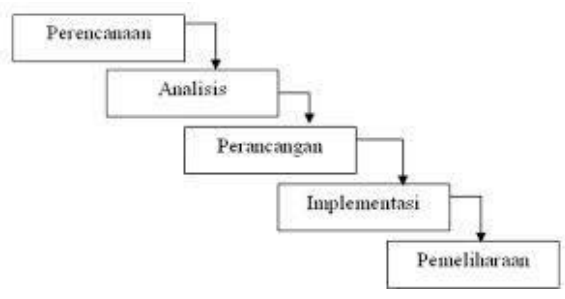

Gambar 1 Waterfall

\section{Analisis Kebutuhan (Requirement)}

Analisis kebutuhan adalah kegiatan menyusun kebutuhan perangkat lunak agar dapat memenuhi solusi pengguna. Analisis dilakukan dengan dasar studi kelayakan yang dilakukan sebelumnya. Analisis kebutuhan merupakan fondasi dari aktivitas berikutnya dalam pengembangan sistem. Hasil analisis kebutuhan dibuat dalam sebuah dokumen untuk memudahkan semua pihak yang terkait dalam pengembangan mengikuti proses pengembangan..

Perancangan(Design)

Perancangan adalah menyusun deskripsi struktur komponen yang akan digunakan dalam pengembangan perangkat lunak. Perancangan sistem dapat berupa dokumen fungsional dan teknis.

Implementasi dan Pengujian (Implementation and Testing)

Penulisan kode adalah tindakan yang dilakukan dalam tahap implementasi pengembangan perangkat lunak. Penulisan kode dilakukan mengikuti desain sistem. Perangkat lunak yang dikembangkan harus mampu melalui tahapan pengujian (verification). Hasil akhir dari tahap ini adalah perangkat lunak yang memiliki kesalahan (bugs) sekecil mungkin. Pengujian dimaksudkan agar perangkat lunak memenuhi kebutuhan sistem. Pengujian dilakukan dengan cara menentukan strategi pengujian, lalu melakukan pengujian dan mebandingkan hasil pengujian dengan hasil yang diharapkan.

Pemeliharaan (maintenance)

Pemilaharaan adalah tahapan dimana perangkat lunak yang dikembnagkan dilingkungan pengembangan mampu digunakan di lingkungan produksi. Penghantaran adalah aktivitas yang dilakukan pertama kali dalam tahap ini. Setelah perangkat lunak sudah digunakan pengguna maka proses pemeliharaan dilakukan berkala sesuai rencana.

\section{J. Pengujian Perangkat Lunak}

Pengujian perangkat lunak merupakan elemen kritis dari jaminan kualitas perangkat lunak dan mempresentasikan kajian pokok dari spesifikasi, desain dan pengkodean.

\section{Pengujian Black-Box}

Pengujian blak-box berfokus pada domain informasi dari perangkat lunak, dengan melakukan test care dengan menpartisi domain input dari suatu program dengan cara memberikan cakupan pengujian yang mendalam. Fungsi untuk menemukan fungsi-fungsi yang tidak benar atau hilang, menemukan kesalahan antarmuka perangkat lunak ${ }^{[17]}$.

\section{Pengujian White-box}

Pengujian White-box merupakan sebuah metode desain uji kasus yang menggunakan struktur kontrol dari desain prosedural untuk menghasilkan kasus-kasus uji. Pengujian didasarkan pada pemeriksaan detail prosedural ${ }^{[18]}$.

\section{PERANCANGAN SISTEM}

\section{A. Analisis Kebutuhan Sistem}

Langkah ini merupakan analisis terhadap kebutuhan sistem. Sistem analisis akan menggali informasi sebanyak-banyaknya dari pengguna sehingga akan tercipta sebuah sistem komputer yang bisa melakukan tugas-tugas yang diinginkan oleh pengguna. Tahapan ini akan menghasilkan dokumen pengguna reqeuirement atau bisa dikatakan sebagai data yang berhubungan dengan keinginan pengguna dalam pembuatan sistem. 


\section{B. Kebutuhan fungsional}

Kebutuhan fungsional merupakan kebutuhan yang meliputi fungsi yang ada pada aplikasi dan berkaitan langsung dengan fitur-fitur pada aplikasi. Secara fungsionalitas sistem, aplikasi ini merupakan aplikasi berbasis satu pengguna (single user). Secara umum, alur sistem aplikasi yang dibuat sebagai berikut.

1. Pengguna membuka aplikasi melalui Smartphone Android yang sudah terinstal aplikasi ini.

2. Pengguna membuka halaman awal pada aplikasio yang beiri tentang, bantuan dan edukasi. Pada halaman edukasi terdapat tombol bagian-bagian dari kerangka tulang manusia beserta fungsinnya.

3. Pengguna dapat mengakses beberapa tombol pilihan pada halaman edukasi.

4. Setelah belajar dan mengenal abgian kerangka tulang manusia, pengguna dapat kemabli pada halaman awal, dengan menekan tombol home pada layar mobile device.

5. Pengguna dapat mengakhiri aplikasi dengan menekan tombol kelaur.

\section{Target Pengguna}

Aplikasi ini dapat dikategorikan menjadi semua unsur, namun untuk target pengguna ini adalah pengguna yang masih berada pada kelas 11 yang tertera pada silabus kurikulum 2013 kelas tersebut dengan bimbingan dari seorang guru yang dapat mengoperasikan Smartphone Android. Aplikasi ini dapat digunakan oleh semua jenis kelamin, baik laki-laki maupun perempuan.

\section{Perancangan Kerangka Pikir Penelitian}

Tahap perancangan kerangka pikir penelitian bertujuan sebagai langkah-langkah dasar penulis dalam penelitian Tugas Akhir. Perancangan kerangka pikir penelitian dengan SDLC (Software Development Life Cycle) sebagai langkah dasar umum dalam perancangan perangkat lunak. Berikut pada Gambar 2 menunjukkan kerangka pikir penelitian.

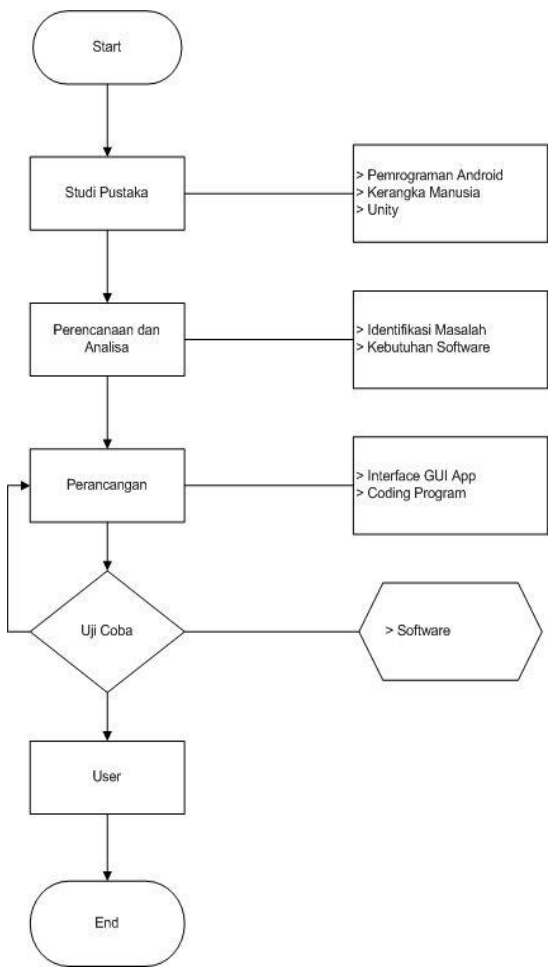

Gambar 2 Kerangka Pikir Penelitian

\section{E. Perancnagan Antarmuka}

Antarmuka adalah suatu bagian yang berhubungan langsung dengan pengguna aplikasi atau biasa disebut dengan nterface aplikasi. Antarmuka dirancang sesuai kebutuhan dari pengguna sebagai sarana pembelajaran edukatif.

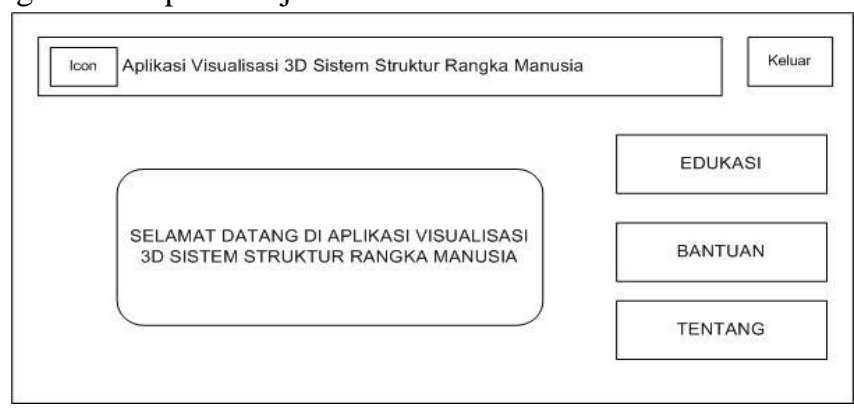

Gambar 3 Tampilan Halaman Awal Aplikasi

\section{F. Perancangan Diagram UML}

Unfield Modelling Language (UML) adalah sebuah standarisasi bahasa pemodelan untuk pembangunan perangkat lunak yang dibangun dengan menggunakan teknik pemrograman berorientasi.

Diagram Use Case mendeskripsikan sebuah interaksi satu atau lebih aktor dengan aplikasi atau sistem infromasi yang akan dibuat. Ada dua hal utama pada use case yaitu aktor dan use case. Berikut penjelasan sederhananya.

1. Aktor merupakan orang, proses atau sistem lain yang berinteraksi dengan aplikasi yang akan dibuat di luar sistem yang akan dibuat sendiri.

2. Use Case merupakan fungsionalitas yang disediakan sistem sebagai unit-unit yang saling bertukaran pesan antar unit atau aktor.

Berikut diagram Use Case dalam perancangan UML.

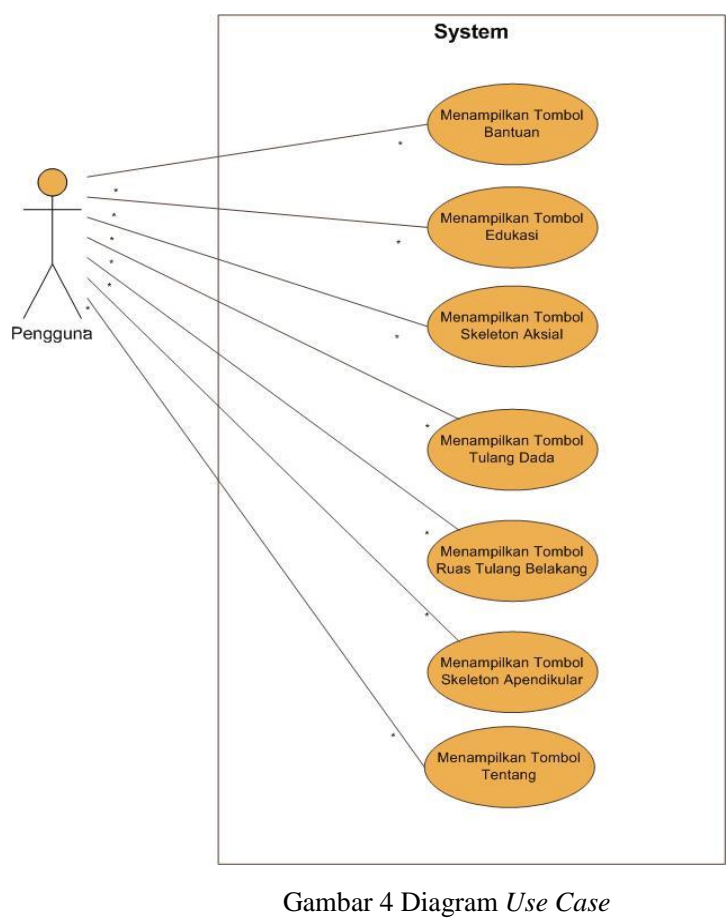

\section{G. Diagram Sequence}

Diagram Sequence menggambarkan kelakuan dari objek pada use case dengan mendeskripsikan waktu hidup dan message yang dikirmkan dan diterima antar objek dalam 
1. Diagram Sequence untuk use case menekan Tombol Edukasi

Diagram Sequence dapat dilihat pada Gambar 5.

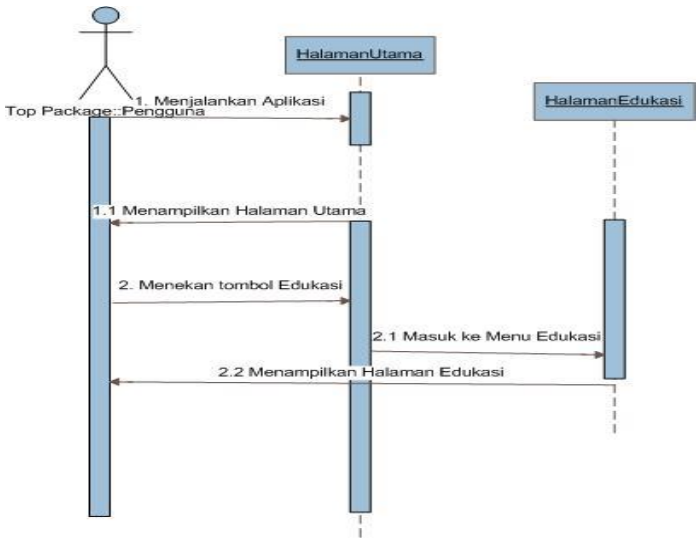

Gambar 5 Diagram Sequence untuk use case Menekan Tombol Edukasi

Diagram di atas menjelaskan bahwa ketika pengguna menjalankan aplikasi dan sistem akan memberikan respon berupa tampilan HalamanUtama dari aplikasi. Kemudian pengguna menekan tombol Edukasi dan akan memanggil kelas ChangeScene dan method HalamanEdukasi () untuk memanggil scene HalamanEdukasi dan sistem akan menampilkan halaman Edukasi.

2. Diagram Sequence untuk use case menekan Tombol Skeleton Aksial

Diagram Sequence dapat dilihar pada Gambar 6.

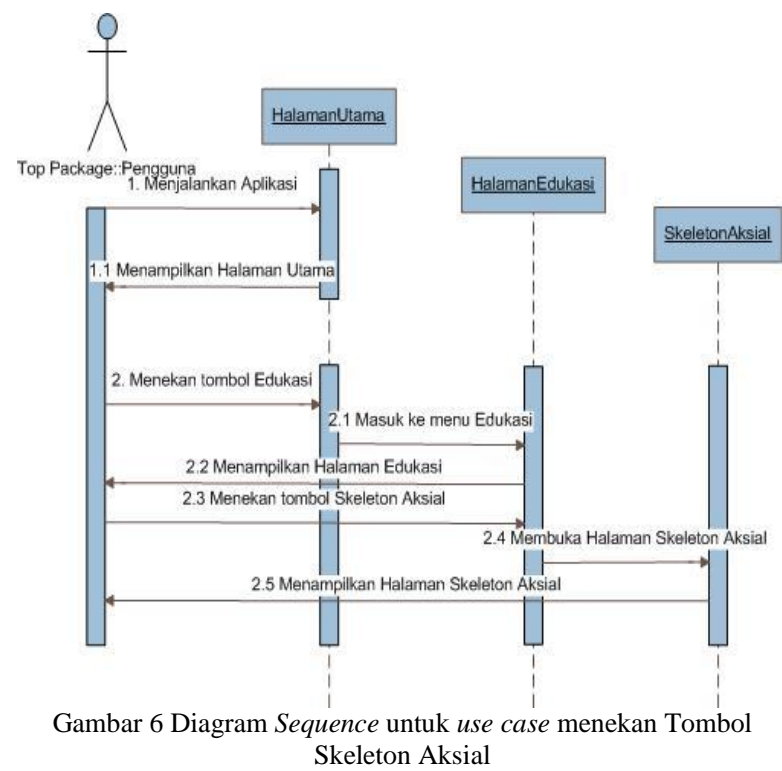

Diagram di atas menjelaskan bahwa ketika pengguna menjalankan aplikasi dan sistem akan memberikan respon berupa tampilan HalamanUtama dari aplikasi. Kemudian pengguna menekan tombol Edukasi dan akan memanggil kelas Changescene dan method HalamanEdukasi() untuk memanggil scene HalamanEdukasi dan sistem akan menampilkan halaman Edukasi. Pada halaman Edukasi pengguna menekan tombol Skeleton Aksial dan akan memanggil kelas ChangeScene dan method SkeletonAksiall() untuk memanggil scene Skeleton Aksial. Sistem akan menampilkan halaman Skeleton Aksial.

\section{H. Diagram Activity}

Diagram Activity menggambarkan workflow (aliran kerja) dari sebuah sistem atau proses bisnis. Berikut dapat dilihat pada Gambar 7 menunjukkan diagram activity.

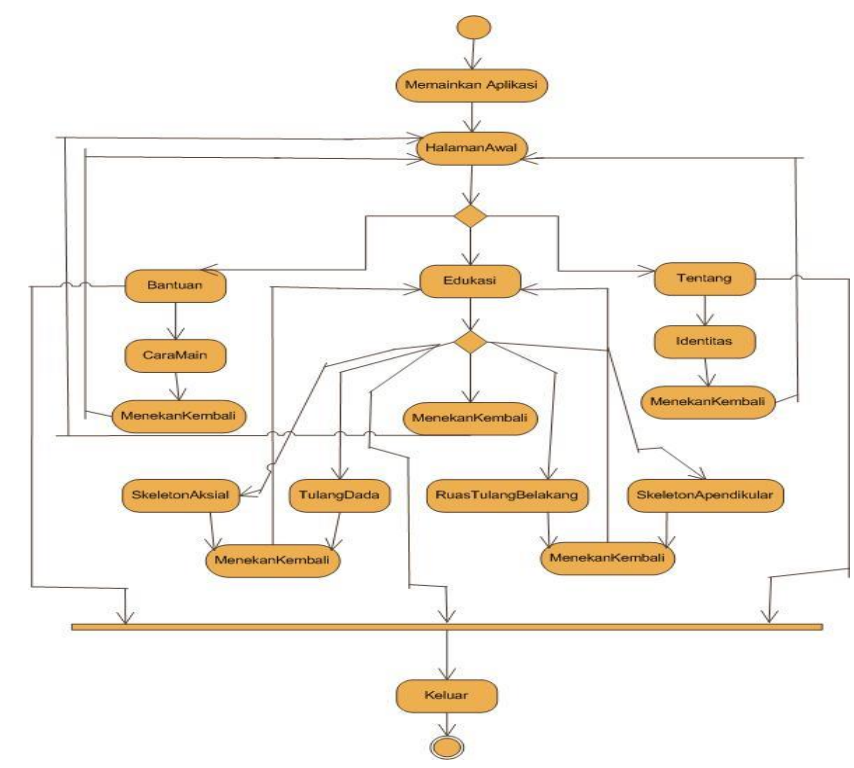

Gambar 7 Diagram Activity

Diagram di atas, aplikasi visualisasi 3D akan dimulai apabila pengguna menjalankan aplikasi. Kemudian akan ditampilkan halaman awal aplikasi visualisasi 3D dengan 3 menu, yaitu menu Bantuan, Edukasi, Tentang. Apabila pemian memilih menu Bantuan, maka akan ditampilkan CaraMain aplikasi dan juga disertai tombol kembali maka akan kembali ke Halaman Awal. Apabila pengguna memilih menu Edukasi maka akan ditampilkan 4 menu yaitu menu Skeleton Aksial, menu Tulang Dada, menu Ruas Tulang Belakang, menu Skeleton Apendikular dan juga disertai tombol kembali yang akan kembali ke Halaman Awal. Apabila pengguna memilih menu Skeleton Aksial di menu Edukasi maka akan ditampilkan penjelasan mengenai skeleton aksial dengan visualisasi 3D struktur rangka manusia dan juga disertai tombol kembali ke halaman Edukasi. Apabila pengguna memilih menu Tulang Dada di menu Edukasi maka akan ditampilkan penjelasan mengenai bagian tulang dada dengan visualisasi 3D struktur rangka manusia dan juga disertai tombol kembali ke halaman Edukasi. Apabila pengguna memilih menu Ruas Tulang Belakang di menu Edukasi maka akan ditampilkan penjelasan mengenai bagian ruas tulang belakang dengan visualisasi 3D struktur rangka manusia dan juga disertai tombol kembali ke halaman Edukasi. Apabila pengguna memilih menu Skeleton Apendikular di menu Edukasi maka akan ditampilkan penjelasan mengenai bagian skeleton apendikular dengan visualisasi 3D struktur rangka manusia dan juga disertai tombol kembali ke halaman Edukasi. Pengguna menekan tombol keluar sebagai akhir dari aplikasi visualisasi 3D pada struktur rangka manusia. 


\section{I.Diagram Kelas}

Diagram Kelas menggambarkan struktur sistem dari segi pendefinisian kelas-kelas apa yang dibuat untuk membangun sistem. Kelas memiliki apa yang disebut atribut dan metode atau operasi. Berikut dapat dilihat pada Gambar 8 menunjukkan diagram kelas.

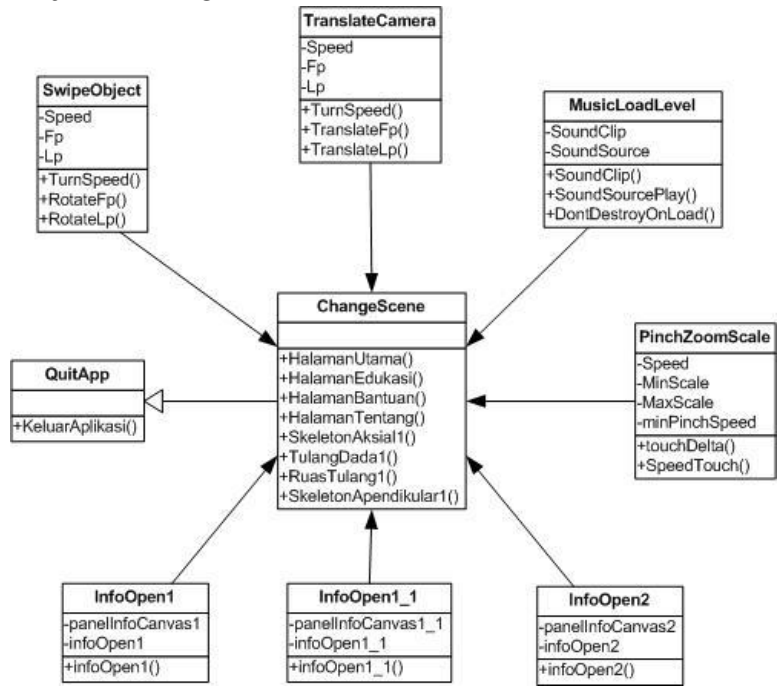

Gambar 8 Diagram Kelas

Berdasarkan diagram di atas, aplikasi visualisasi 3D memiliki kelas-kelas seperti yang tertera pada gambar di atas. Pada pemrograman Unity 3D penulis gunakan, bahasa pemrograman JavaScript untuk menjalankan fungsi-fungsi penulis yang sudah rancang. Di mulai dari kelas ChangeScene disini memiliki metode HalamanUtama(), HalamanEdukasi(), HalamanBantuan(), HalamanTentang(), SkeletonAksial(), TulangDada1(), RuasTulang1(), Skeleton Apendikular()yang berfungsi sebagai penghubung scene yang satu dengan yang lainnya ketika pengguna menekan fungsi tombol. Kemudian terdapat kelas QuitApp memiliki metode KeluarAplikasi() yang berfungsi mengakhiri penggunaan aplikasi ketika pengguna ingin mengakhiri aplikasi. Kemudian terdapat kelas SwipeObject yang berfungsi merotasikan objek pada setiap scene, kelas TranslateCamera yang berfungsi menggerakkan kamera utama ketika objek bergerak ke sumbu y atau -y (atas atau bawah), kelas PinchZoomScale yang berfungsi untuk memperbesar dan memperkecil objek dengan batasan, kelas MusicLoadLevel yang berfungsi untuk menjalankan musik tetap menyala (on) disetiap scene dan kelas InfoOpen1, InfoOpen1_1, InfoOpen2 yang berfungsi untuk jendela popup pada scene yang dibuat

\section{IMPLEMENTASI DAN PENGUJIAN}

Implementasi aplikasi dilakukan sesuai hasil perancangan dari Bab III, sehingga dihasilkan suatu aplikasi pembelajaran yang bekerja sesuai dengan fungsinya. Sedangkan pengujiannya dilakukan dengan metode black-box, serta akan dilakukan juga uji survei pengguna kepada pengguna.

\section{A. Pembuatan}

Pembuatan aplikasi dilakukan dengan membuat project baru. Dapat dikatakan pula bahwa project dalam Unity 3D terdiri atas scene yang akan dibuat dan menggunakan JavaScript sebagai bahasa pemrograman objek untuk menjalankan scene yang akan dibuat. Gambar 8 merupakan hasil pembuatan project pertama pada scene HalamanUtama.

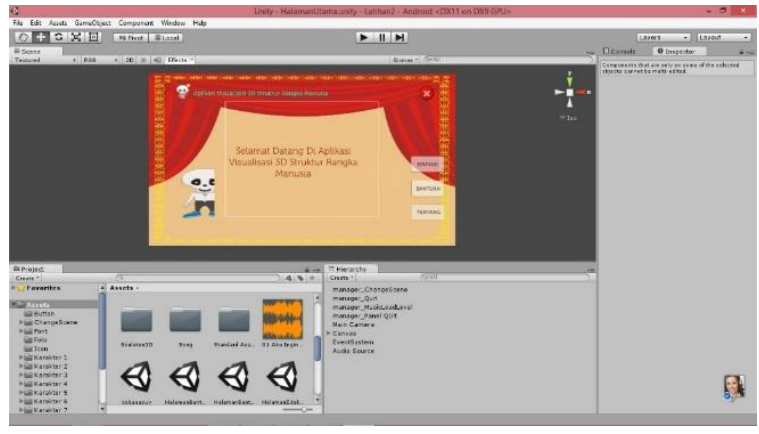

Gambar 9 Scene Halaman Utama

Tahap berikutnya yaitu pembuatan scene utama, dimana scene yang terdapat objek kerangka 3D. Tahapan awal objek kerangka 3D pada scene sebagai berikut.

1. Objek kerangka 3D hasil dari download situs web gratis ${ }^{[16]}$.

2. Kemudian objek kerangka 3D tersebut di ubah file ekstensinya dari .skp menjadi .obj dikarenakan pada Unity 3D objek kerangka 3D yang digunakan berupa berkas .obj.

3. Objek kerangka 3D tersebut di export > 3D Models > file ekstensinya diubah menjadi .obj pada Google SketchUp. Berikut pada Gambar 9.

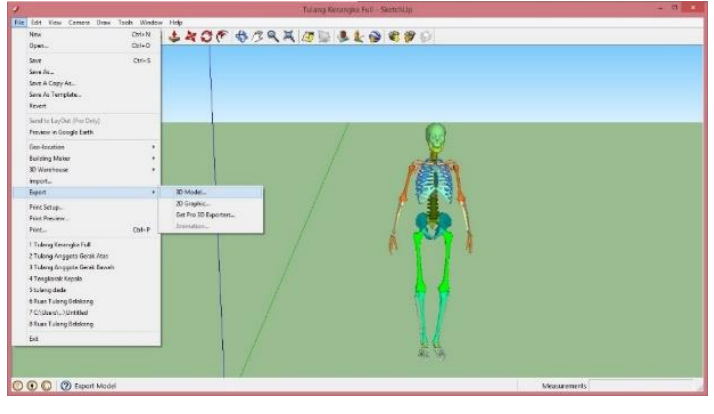

Gambar 9 Eksport Objek

4. Langkah terakhir adalah men-drag file .obj dengan menahan bagian kiri mouse pindahkan ke project > assets > New Folder ganti nama foldernya untuk menyimpan file kerangka 3D.obj pada Unity3D. Berikut pada Gambar 10.

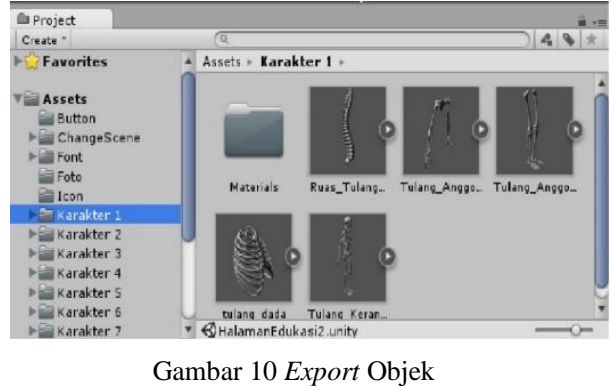

Berikut langkah-langkah untuk memanipulasi objek kerangka 3D dengan memberikan warna sesuai dengan scene yang dimaksud sebagai berikut.

1. Drag objek yang telah terekstensikan dengan file .obj ke assets pada Unity3D kemudian berilah skala pembesaran objek dan posisi yang tepat pada layar scene pada lembar inspector. Gambar 11 merupakan gambar inspector objek kerangka 3D. 


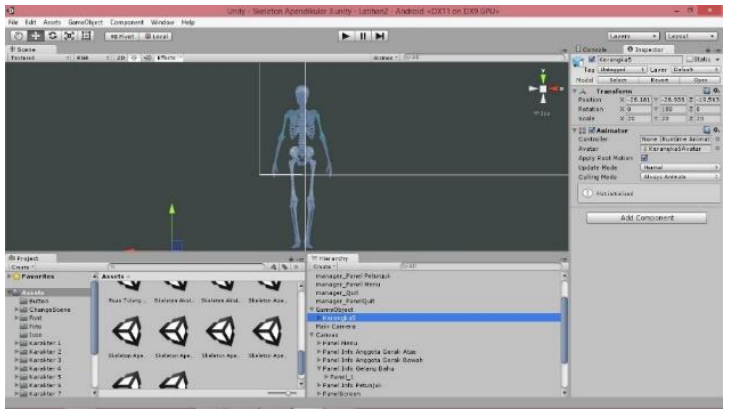

Gambar 11 Inspektor Objek

2. Berikan cahaya pada objek berupa directional light dan atur posisi cahaya tersebut agar objek dapat terlihat pada layar kamera seperti berikut pada Gambar 12.

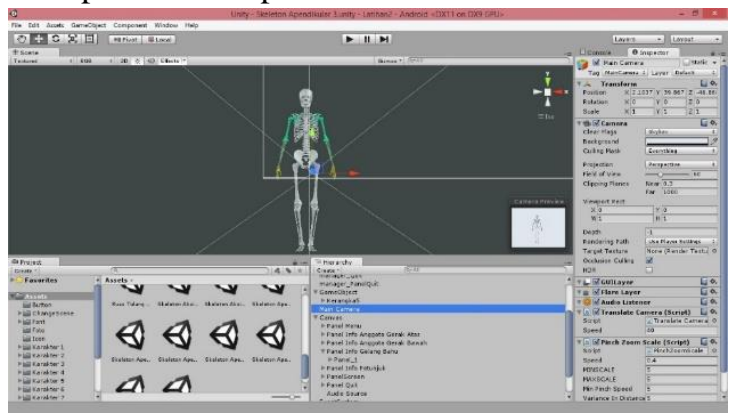

Gambar 12 Camera Preview

3. Kemudian double click pada objek kerangka 3D pada lembar hierarchy Unity3D, akan nampak mesh-mesh kerangka objek kerangka 3D,pilih bagian tersebut sesuai dengan pembagian yang telah dirancang. Pada lembar inspector plih mesh kerangka yang sudah dipilih kemudian klik pada main color akan tampil jendela color Unity3D kemudian berikan masukan angka pada R,G,B Unity3D dan objek kerangka 3D sudah diberikan warna seperi berikut pada Gambar 13 .

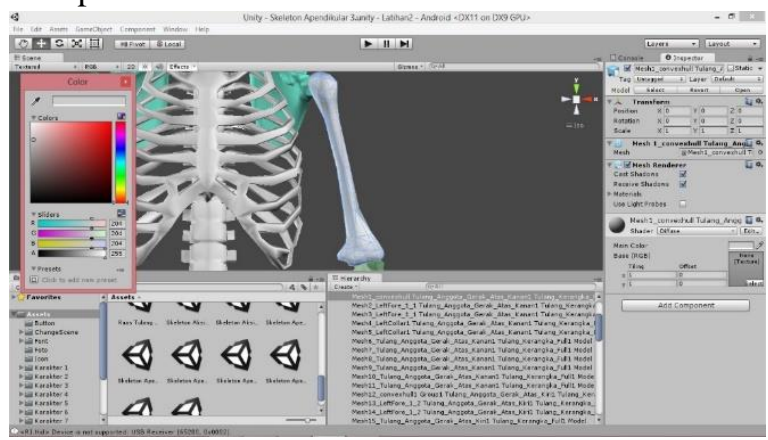

Gambar 13 Setting Colour

Setelah memanipulasi objek dengan pemberian warna pada bagian tulang manusia, berikutnya yaitu berupa tampilan keseluruhan pada scene yang terdapat objek kerangka 3D, dimana scene-scene yang terdapat objek kerangka 3D, pengguna dapat memutar objek, memperbesar dan memperkecil objek, dan menggeser objek pada saat objek mengalami pembesaran untuk melihat bagian objek yang lainnya. Gambar 14 merupakan tampilan scene yang terdapat objek kerangka 3D.

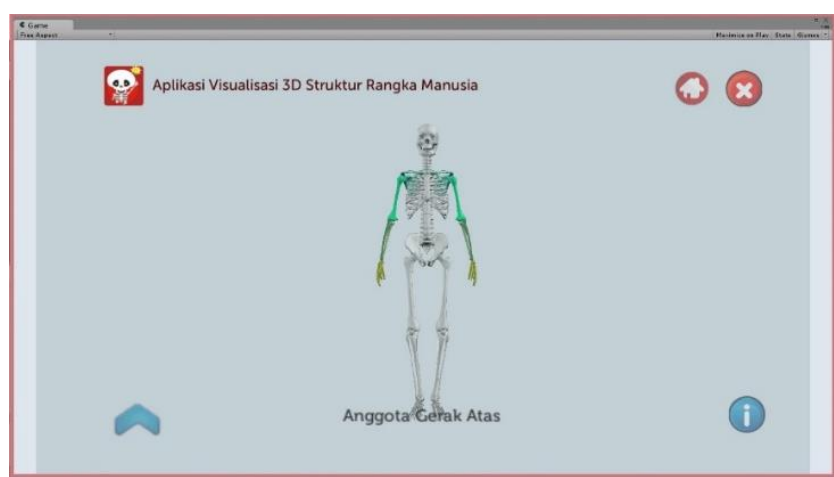

Gambar 14. Scene Objek Kerangka3D

\section{Pengujian}

Pengujian aplikasi dilakukan dengan menggunakan metode black-box, dengan kata lain pengujian yang menekankan pada fungsionalitas dari aplikasi. Tahap ini berisi serangkaian pengujian fungsi dan tombol pada aplikasi. Tingkat keberhasilan pengujian, diukur dari terpenuhinya spesifikasi kebutuhan dan skenario aplikasi. Pengujian permainan dijalankan pada smartphone yang menggunakan sistem operasi Android. Cara pengujiannya hanya dilakukan dengan menjalankan aplikasi, kemudian diamati apakah hasilnya sesuai dengan spesifikasi kebutuhan.

TABEL I

PENGUJIAN APLIKASI SECARA KESELURUHAN

\begin{tabular}{|c|c|c|c|}
\hline $\begin{array}{c}\text { Nama } \\
\text { Pengujian }\end{array}$ & $\begin{array}{c}\text { Bentuk } \\
\text { Pengujian }\end{array}$ & $\begin{array}{c}\text { Hasil yang } \\
\text { Diharapkan }\end{array}$ & $\begin{array}{c}\text { Hasil } \\
\text { Pengujian }\end{array}$ \\
\hline Loading & $\begin{array}{l}\text { Membuka } \\
\text { aplikasi }\end{array}$ & $\begin{array}{l}\text { Tampil icon Unity } \\
\text { Loading } \\
\text { selanjutnya } \\
\text { muncul halaman } \\
\text { awal }\end{array}$ & Berhasil \\
\hline $\begin{array}{l}\text { Pengujian } \\
\text { menu Bantuan }\end{array}$ & $\begin{array}{l}\text { Menekan } \\
\text { tombol } \\
\text { Bantuan }\end{array}$ & $\begin{array}{l}\text { Tampil halaman } \\
\text { Bantuan aplikasi }\end{array}$ & Berhasil \\
\hline $\begin{array}{l}\text { Pengujian } \\
\text { menu Tentang }\end{array}$ & $\begin{array}{l}\text { Menekan } \\
\text { tombol } \\
\text { Tentang }\end{array}$ & $\begin{array}{l}\text { Tampil halaman } \\
\text { Tentang }\end{array}$ & Berhasil \\
\hline $\begin{array}{l}\text { Pengujian } \\
\text { menu Edukasi }\end{array}$ & $\begin{array}{l}\text { Menekan } \\
\text { tombol } \\
\text { Edukasi }\end{array}$ & $\begin{array}{l}\text { Tampil halaman } \\
\text { Edukasi }\end{array}$ & Berhasil \\
\hline $\begin{array}{l}\text { Pengujian } \\
\text { menu Keluar }\end{array}$ & $\begin{array}{l}\text { Menekan } \\
\text { tombol Keluar }\end{array}$ & $\begin{array}{l}\text { Keluar dari } \\
\text { aplikasi }\end{array}$ & Berhasil \\
\hline
\end{tabular}

\section{Pengujian Fungsi Aplikasi}

Pengujian fungsi ini merupakan pengujian internal fungsional pada aplikasi ini berupa SwipeObject, PinchZoom, dan ShiftObject. Pengujian ini akan menggunakan pengujian white box, dimana setiap fungsi yang ada akan diuji rinci jalurjalur logika yang ada.

Pada tahap pertama, fungsi SwipeObject yang berfungsi untuk menggerakan objek dan memutar objek pada sumbu $\mathrm{x}$. Fungsi didaparkan flowchart' seperti pada gambar 15.

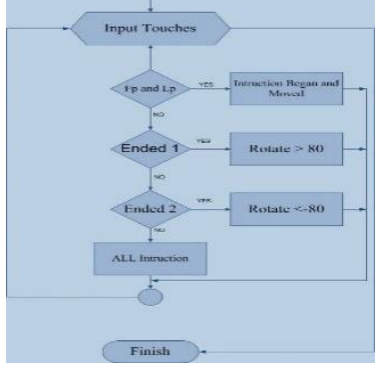


Proses pertama adalah menyentuh layar untuk menggeserkan objek ketika pengguna menyentuh layar (Input Touches) ada beberapa fungsi, pertama adalah posisi jari awal menyentuh layar (First Position/Fp) dan kedua posisi jari terahir artinya jari tersebut sudah dan selesai digerakkan (Last Position/LP) dan kemudian menjalankan intruksi mulai (Began) dan intruksi sudah atau selesai (Moved).

Pada gambar 16 ditunjukkan Flowgraph dari proses SwipeObject, dan dihasilkan jalur seperti pada tabel 2. Dari Flowgraph didapatkan nilai cyclomatic complexity $\mathrm{V}(\mathrm{G})=\mathrm{E}$ $\mathrm{N}+2$ atau $\mathrm{V}(\mathrm{G})=\mathrm{P}+1$, dimana $\mathrm{E}$ merupakan jumlah Edge, $\mathrm{N}$ merupakan jumlah Node, sedangkan $\mathrm{P}$ merupakan jumlah cabang, sehingga $\mathrm{V}(\mathrm{G})=3+1=4$.

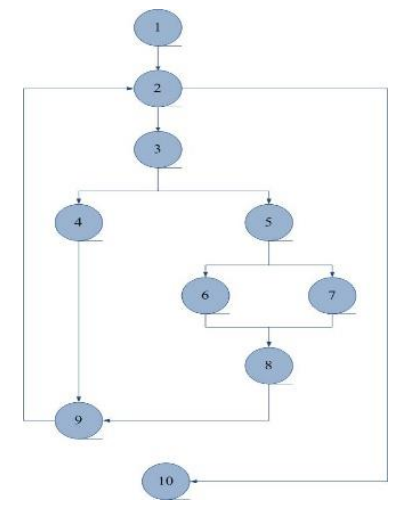

Gambar 16. Flowgrapht SwipeObject

TABEL II

FLOWGRAPH SWIPEOBJECT

\begin{tabular}{|c|c|c|}
\hline Jalur & Tahapan & Keterangan \\
\hline 1 & $1-2-3-4-9-2-10$ & Proses Moved \\
\hline 2 & $\begin{array}{l}1-2-3-5-6-8-9-2- \\
10\end{array}$ & Proses Ended1 \\
\hline 3 & $\begin{array}{l}1-2-3-5-7-8-9-2- \\
10\end{array}$ & Proses Ended2 \\
\hline 4 & $1-2-10$ & Proses Gagal \\
\hline
\end{tabular}

Pada tahap kedua, fungsi PinchZoom, berfungsi untuk memperbesarkan dan memperkecil objek dengan menyentuhkan jari kemudian menggeser untuk memperbesar dan memperkecil objek. Fungsi didapatkan flowchart seperti pada gambar 17 .

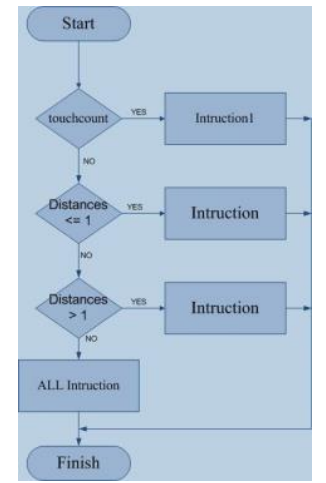

Gambar 17. Flowchart PinchZoom

Pada proses kedua ini untuk memperbesar dan memperkecil, yang tentunya dengan banyak sentuhan (touchcount) yang terjadi ketika awal pengguna untuk mencoba aplikasi. Keadaan tersebut tentunya akan ada intruksi sistem yang akan dikerjakan.

Jurnal Teknologi dan Sistem Komputer, Vol.3, No.4, Oktober 2015 (e-ISSN: 2338-0403)
Pada gambar 18 ditunjukkan Flowgraph dari proses PinchZoom, dan dihasilkan jalur seperti pada tabel 3. Dari Flowgraph didapatkan nilai cyclomatic complexity $\mathrm{V}(\mathrm{G})=\mathrm{E}$ $\mathrm{N}+2$ atau $\mathrm{V}(\mathrm{G})=\mathrm{P}+1$, dimana $\mathrm{E}$ merupakan jumlah Edge, $\mathrm{N}$ merupakan jumlah Node, sedangkan $P$ merupakan jumlah cabang, sehingga $\mathrm{V}(\mathrm{G})=2+1=3$

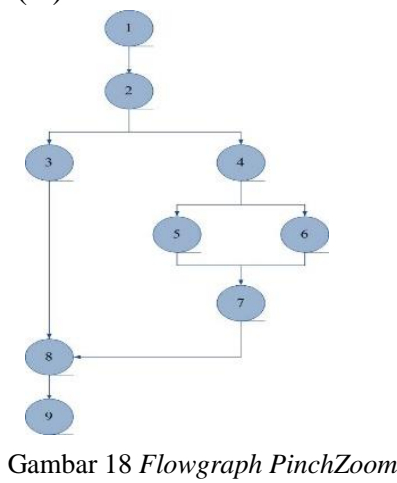

TABEL III

FLOWGRAPH PINCHZOOM

\begin{tabular}{lcl}
\hline \hline Jalur & Tahapan & Keterangan \\
\hline 1 & $1-2-4-5-7-8-9$ & $\begin{array}{l}\text { Proses } \\
\text { Dstances }<=1\end{array}$ \\
2 & $1-2-4-6-7-8-9$ & $\begin{array}{l}\text { Proses } \\
\text { Distances }>1\end{array}$ \\
3 & $1-2-3-8-9$ & Proses gagal \\
\hline \hline
\end{tabular}

Pada tahap terakhir, fungsi ShiftObject, berfungsi untuk menggeser objek ke arah atas (sumbu y) atau ke arah bawah (sumbu $-y)$. Fungsi didpaatkan flowchart pada gambar 19.

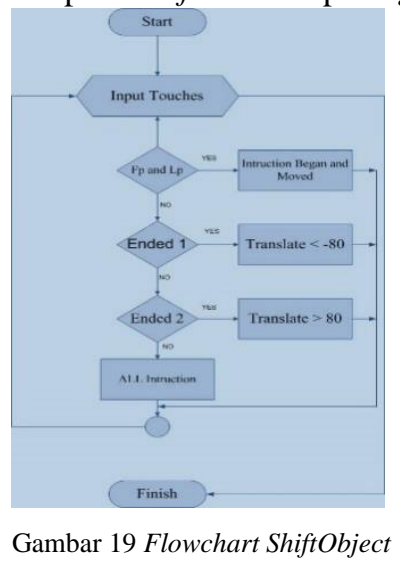

Proses pertama adalah menyentuh layar untuk menggeserkan objek ketika pengguna menyentuh layar (Input Touches) ada beberapa fungsi, pertama adalah posisi jari awal menyentuh layar (First Position/Fp) dan kedua posisi jari terahir artinya jari tersebut sudah dan selesai digerakkan (Last Position/LP) dan kemudian menjalankan intruksi mulai (Began) dan intruksi sudah atau selesai (Moved).

Pada gambar 20 ditunjukkan Flowgraph dari proses ShiftObject, dan dihasilkan jalur seperti pada tabel 4. Dari Flowgraph didapatkan nilai cyclomatic complexity $\mathrm{V}(\mathrm{G})=\mathrm{E}$ $\mathrm{N}+2$ atau $\mathrm{V}(\mathrm{G})=\mathrm{P}+1$, dimana $\mathrm{E}$ merupakan jumlah Edge, $\mathrm{N}$ merupakan jumlah Node, sedangkan $\mathrm{P}$ merupakan jumlah cabang, sehingga $V(G)=3+1=4$.

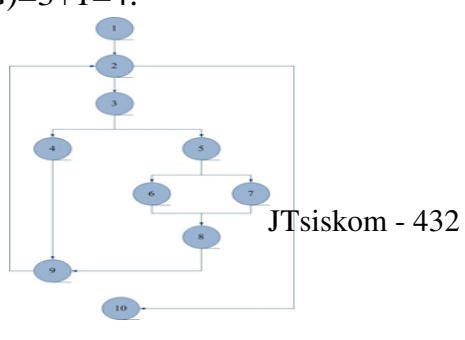


Gambar 20 Flowgraph ShiftObject

TABEL IV

FLOWGRAPH SWIPEOBJECT

\begin{tabular}{lll}
\hline \hline Jalur & \multicolumn{1}{c}{ Tahapan } & Keterangan \\
\hline 1 & $1-2-3-4-9-2-10$ & Proses Moved \\
2 & $1-2-3-5-6-8-9-2-$ & Proses Ended1 \\
& 10 & \\
3 & $1-2-3-5-7-8-9-2-$ & Proses Ended 2 \\
& 10 & \\
4 & $1-2-10$ & Proses Gagal \\
\hline \hline
\end{tabular}

\section{Pengujian Aplikasi Menggunakan Kuesioner}

Untuk mengetahui secara langsung manfaat aplikasi bagi pengguna, penulis melakukan survey skala penilaian atau rating scale yang kemudian dihitung menggunakan skala Likert untuk mengubahnya dalam bentuk persentase.

Proses pengujian dilakukan dengan cara meminta responden untuk menjawab 5 sempel pertanyaan dimana setiap pertanyaan terdapat 2 pilihan jawaban, yaitu Iya dan Tidak. Pada setiap sample pertanyaan yang diberikan, untuk penilaian Iya diberi bobot skor 2 dan Tidak diberi bobot skor 1 . Digunakan rumus skala Likert sebagai berikut:

$$
Y=\frac{X}{\text { skor ideal }} \times 100 \%
$$

Keterangan :

$\mathrm{X} \quad=$ Jumlah frekuensi dikalikan dengan nilai kategori jawaban

Skor ideal $=$ Nilai tertinggi dikalikan dengan jumlah sampel

$\mathrm{Y} \quad=$ Nilai persentase yang dicari

Tabel V menunjukkan hasil pengujian kuesioner yang diberikan dengan sample pertanyaan aplikasi "Visualisasi 3D Pada Struktur Sistem Rangka Manusia" mudah dalam penggunaannya, setelah responden menggunakan aplikasi ini dan kemudian dihitung nilainya dengan menggunakan rumus skala Likert.

TABEL V

HASIL PENGUJIAN KuESIONER

\begin{tabular}{lcccc}
\hline \hline Soal & Keterangan & Skor & Responden & Skor Responden \\
\hline 1 & Iya & 2 & 13 & 26 \\
& Tidak & 1 & 12 & 12 \\
& Jumlah & & 25 & 38 \\
\hline \hline
\end{tabular}

Berdasarkan perhitungan menurut rumus skala Likert maka didapatkan hasil sebagai berikut ini.

$$
Y=\frac{a \mathrm{~g}}{25 \times 2} \times 100 \%=76 \%
$$

Berdasarkan hasil persentase nilai di atas, maka dapat disimpulkan bahwa berdasarkan pertanyaan yang diberikan, responden mudah dalam menggunakan aplikasi ini.

Tabel VI menunjukkan hasil pengujian kuesioner yang diberikan dengan sample pertanyaan tampilan Aplikasi "Visualisasi 3D Pada Struktur Sistem Rangka Manusia" secara keseluruhan bagus dan menarik, setelah responden menggunakan aplikasi ini dan kemudian dihitung nilainya dengan menggunakan rumus skala Likert.

TABEL VI

HASIL PENGUJiAn KuESIONER

\begin{tabular}{ccccc}
\hline \hline Soal & Keterangan & Skor & Responden & Skor Responden \\
\hline 1 & Ya & 2 & 14 & 28 \\
& Tidak & 1 & 11 & 11 \\
& Jumlah & & 25 & 39 \\
\hline \hline
\end{tabular}

Berdasarkan perhitungan menurut rumus skala Likert maka didapatkan hasil sebagai berikut ini.

$$
Y=\frac{99}{25 \times 2} \times 100 \%=78 \%
$$

Berdasarkan hasil persentase nilai di atas, maka dapat disimpulkan bahwa berdasarkan pertanyaan yang diberikan, responden cukup tertarik dengan tampilan aplikasi secara keseluruhan.

Tabel VII menunjukkan hasil pengujian kuesioner yang diberikan dengan sample pertanyaan tampilan Aplikasi "Visualisasi 3D Pada Struktur Sistem Rangka Manusia" sudah menyediakan media pembelajaran praktis dan menarik, setelah responden menggunakan aplikasi ini dan kemudian dihitung nilainya dengan menggunakan rumus skala Likert.

TABEL VII HASIL PENGUJIAN KUESIONER

\begin{tabular}{lcccc}
\hline \hline Soal & Keterangan & Skor & Responden & Skor Responden \\
\hline 1 & Ya & 2 & 16 & 32 \\
& Tidak & 1 & 9 & 9 \\
& Jumlah & & 25 & 41 \\
\hline \hline
\end{tabular}

Berdasarkan perhitungan menurut Rumus Likert maka didapatkan hasil sebagai berikut ini.

$$
Y=\frac{41}{25 \times 2} \times 100 \%=80 \%
$$

Berdasarkan hasil persentase nilai di atas, maka dapat disimpulkan bahwa berdasarkan pertanyaan yang diberikan, responden setuju jika aplikasi ini praktis dan menarik sebagai media pembelajaran.

Tabel VIII menunjukkan hasil pengujian kuesioner yang diberikan dengan sample pertanyaan tampilan Aplikasi "Visualisasi 3D Pada Struktur Sistem Rangka Manusia" bernanfaat dalam pembelajaran, setelah responden menggunakan aplikasi ini dan kemudian dihitung nilainya dengan menggunakan rumus skala Likert

TABEL VIII

HASIL PENGUJIAN KUESIONER

\begin{tabular}{ccccc}
\hline \hline Soal & Keterangan & Skor & Responden & Skor Responden \\
\hline 1 & Ya & 2 & 19 & 38 \\
& Tidak & 1 & 6 & 6
\end{tabular}


Berdasarkan perhitungan menurut Rumus Likert maka didapatkan hasil sebagai berikut ini.

$$
Y=\frac{44}{25 \times 2} \times 100 \%=88 \%
$$

Berdasarkan hasil persentase nilai di atas, maka dapat disimpulkan bahwa berdasarkan pertanyaan yang diberikan, responden sangat setuju karena aplikasi bermanfaat sesuai target pengguna.

Tabel IX menunjukkan hasil pengujian kuesioner yang diberikan dengan sample pertanyaan tampilan Aplikasi "Visualisasi 3D Pada Struktur Sistem Rangka Manusia" menarik kembali digunakan, setelah responden menggunakan aplikasi ini dan kemudian dihitung nilainya dengan menggunakan rumus skala Likert

TABEL IX

HASIL PENGUJIAN KUESIONER

\begin{tabular}{lcccc}
\hline \hline Soal & Keterangan & Skor & Responden & Skor Responden \\
\hline 1 & Ya & 2 & 17 & 34 \\
& Tidak & 1 & 8 & 8 \\
& Jumlah & & 25 & 42 \\
\hline \hline
\end{tabular}

Berdasarkan perhitungan menurut Rumus Likert maka didapatkan hasil sebagai berikut ini.

$$
Y=\frac{42}{25 \times 2} \times 100 \%=84 \%
$$

Berdasarkan hasil persentase nilai di atas, maka dapat disimpulkan bahwa berdasarkan pertanyaan yang diberikan, responden sangat setuju karena aplikasi bermanfaat sesuai target pengguna.

\section{Pembahasan}

Hasil pengujian menggunakan metode black-box, menunjukkan bahwa permainan sudah berjalan sesuai dengan spesfikasi kebutuhan. Hal ini tampak pada tabel-tabel pengujian tombol yang menampakkan hasil uji "Berhasil" pada fungsi-fungsi dalam aplikasi dan "Berhasil" pada penggesaran objek untuk berputar serta pembesaran objek. Secara fungsional, aplikasi ini dapat menghasilkan keluaran yang diharapkan. Aplikasi ini ada kelebihan dan kekurangan pada saat penggunaannya sebagai berikut.

Adapun kelebihan dari aplikasi visualisasi 3D pada struktur rangka manusia berbasis Android ini adalah

1. Aplikasi sebagai sarana pembelajaran mata pelajaran biologi mengenal bagian-bagian dari struktur rangka tubuh manusia.

2. Aplikasi ini dapat dijalankan pada sistem Android.

3. Aplikasi mudah digunakan sebagai sarana pembelajaran, sehingga menarik perhatian siswa-siswi untuk menggunakan aplikasi ini kembali dengan penilaian yang diberikan pengguna, dimana semua penilaian aspek tersebut mendapatkan persentase rata-rata $81,2 \%$.

Adapun kekurangan dari aplikasi visualisasi 3D pada struktur rangka manusia berbasis Android ini adalah

1. Aplikasi ini tidak menampilkan objek anatomi secara lengkap.

2. Tidak ada penggambaran (visualisasi) 3D mengenai kerusakan atau kecacatan struktur rangka tubuh manusia serta penjagaan dari kerusakan tersebut.

3. Untuk dapat menggunakan aplikasi ini, harus membutuhkan sistem operasi Android tidak dapat dijalankan pada sistem Android.

\section{KESIMPULAN DAN SARAN}

Pada bagian ini akan dijelaskan kesimpulan dan saran dari hasil penelitian dan pembahasan.

\section{A. Kesimpulan}

Kesimpulan dari penelitian Tugas Akhir ini di antaranya sebagai berikut :

1) Permainan ini dibuat menggunakan Unity3D dan dapat berjalan baik pada sistem operasi Android, serta hasil dari pengujian permainan dengan menggunakan metode blackbox mendapatkan hasil bahwa tombol-tombol dan fungsifungsi yang terdapat pada permainan dapat berfungsi dengan baik dan sesuai dengan fungsionalitasnya masingmasingPermainan ini berisi tentang belajar angka dan huruf hijaiyah dalam sebuah aplikasi game.

2) Aplikasi ini dirancang dengan menggunakan metode waterfall, yang merupakan pendekatan yang sistematis dan berurutan pada pengembangan perangkat lunak dalam menentukan spesifikasi kebutuhan dan berlanjut melalui tahapan. Tahapan yang secara umum adalah analisis kebutuhan, perancangan, implementasi, pengujian dan pemiliharaan.

3) Berdasarkan hasil olahan data kuesioner dari 25 orang yang diambil sebagai responden menunjukkan angka 76-84\%, maka responden cukup tertarik menggunakan aplikasi ini sebagai media pembelajaran Permainan dapat dijalankan pada sistem operasi android dengan cara melakukan instalasi aplikasi file dengan format .apk terlebih dahulu sebelum memainkannya.

\section{B. Saran}

Saran yang dapat diberikan oleh penulis adalah sebagai berikut :

1) Aplikasi yang sudah dibuat sudah berjalan dengan baik sesuai dengan tujuan awal namun masih perlu dilakukan penelitian lanjutan untuk pengembangan aplikasi ini.

2) Penambahan animasi pada pergerakan masing-masing objek kerangka 3D agar tervisualisasikan lebih hidup dan efek pada gambar agar tampilan terlihat lebih menarik dan pengguna tidak merasa bosan dengan aplikasi ini.

3) Penambahan dan pengkajian materi secara terperinci seperti pembelajaran anatomi tubuh pada aplikasi berbasis Android agar pengguna mengetahui secara lebih terperinci sistem yang terdapat dalam tubuh manusia beserta fungsinya.

\section{DAFTAR PUSTAKA}

[1] Suyanto, M., Multimedia Alat Untuk Meningkatkan Keunggulan Bersaing, CV. Andi Offset, Yogyakarta, 2003.

[2] Miftah, Struktur dan Fungsi Rangka Tubuh Manusia, http://blog-uinmalang.ac.id/tergaptek/page/4, Januari 2013.

[3] Arafik, Visualisasi 3 Dimensi Gedung Fakultas Sains dan Teknologi UIN Syarif Hidayatullah, UIN Syarif Hidayatullah, Jakarta, 2010. 
[4] Anom, T.F., Visualisasi 3 Dimensi Struktur Rangka Pada Manusia, Skripsi S-1, Universitas Islam Negeri Syarif Hidayatullah Jakarta, Jakarta, 2011

[5] Basuki, A., Grafik 3 Dimensi, Politeknik Elektronika Negeri Surabaya, Surabaya, 2009.

[7] Rachmawati, F., dkk, Biologi: Untuk SMA/MA Kelas X1 Program IPA, Pusat Perbukuan Departemen Pendidikan Nasional, Jakarta, 2009.

[8] Nurhayati, N., dkk., Biologi : Untuk SMA/MA Kelas X1 Kelompok Peminatan Matematika dan Ilmu-Ilmu Alam, Penerbit Yrama Widya, Bandung, 2014.

[9] Safaat,H.N., Pemrograman Aplikasi Mobile Smartphone Dan Tablet PC Berbasis Android, Penerbit INFORMATIKA, Bandung, 2012.

[10] Safaat,H.N., Aplikasi Berbasis Android, Penerbit INFORMATIKA, Bandung, 2013.

[11] Tantra, R., Manajemen Proyek Sistem Informasi, CV. Andi Offset, Yogyakarta, 2012.

[12] Pressman, R.S., Rekayasa Perangkat Lunak, CV. Andi Offset, Yogyakarta, 2012.

[13] Sholahuddin, M., Modul Pembelajaran : Rekayasa Perangkat Lunak (Terstruktur Dan Berorientasi Objek), MODULA, Bandung, 2011.

[14] ---,Computer Networks, http://3dwarehouse.sketchup.com/model, 28 September 2014

[15] Roedavan, R., Unity Tutorial Game Engine, penerbit INFORMATIKA, Bandung, 2014.

[16] ---,Computer Networks, https://wsifi.staff.gunadarma.ac.id/Downloads/files/5126/Dasa r Pengujian_Perangkat_Lunak.pdf

[17] ---,Computer Networks, https://webunair.ac.id/admin/file/f_33720_rpl_8_Pengujian_Perangkat_L unak.pdf 